\title{
Pesquisa...educação...um olhar sobre a formação docente no estágio curricular supervisionado em artes visuais
}

Angélica Neuscharank ${ }^{i}$

Universidade Federal de Santa Maria

\section{Resumo}

Esta escrita se propõe a compartilhar algumas experiências referentes a docência orientada realizada na disciplina de estágio curricular supervisionado, no curso de graduação em Artes Visuais, tendo em vista, o olhar para com o professorpesquisador e a potencialidade da problematização nesses espaços formativos. Trata-se de experienciar as diferentes instâncias da docência no ensino superior em uma disciplina que vivencia os processos de formação de professores. O intuito é contar sobre os encontros que tivemos, sobre a produção de escritas a partir das leituras realizadas, e as ressonâncias das mesmas nas orientações dos projetos de ensino e pesquisa, nos planejamentos das aulas, nas inserções e assistências nas escolas, nos processos avaliativos e na produção de instrumentos que possam acompanhar esses percursos.

Palavras-chave: estágio; docência; pesquisa; educação; problematização.

\section{Research... Education... a glance at teaching formation in the curricular supervised teaching training in Visual Arts}

\begin{abstract}
This writing proposes to share some experiences concerning the guided teaching practice developed in the curricular supervised teaching training course, of a Visual Arts Major, focusing on the researcher-teacher and the potentiality of problematization in these formative spaces. It is about experiencing different instances of teaching in higher education in a course that explores the teachers' formation processes. The aim is to report the meetings we had, the production of writings considering the readings performed, and their resonances in the advising of the teaching and research projects, in the lesson plans, in the school insertions and observance, in the evaluative processes, and in the production of instruments that can follow these paths.
\end{abstract}

Keywords: teaching training; teaching; research; education; problematization.

\section{Introdução}

Penso na escrita deste texto, enquanto um espaço de partilhas, de generosidade com vocês, leitores, que trabalham ou poderão vir a trabalhar com a formação docente em artes visuais. Intento que possam olhar para as experiências que mais os afetarem, e que, portanto, possam questionar, desdobrar e recriar estas escritas. Digo isto, pois o artigo não pretende expor as práticas como normatizações no modo de atuação docente em disciplinas de estágio curricular, 
mas apresentar algumas possibilidades para pensarmos "o quê" trabalhar com estes professores em formação inicial.

As experiências que serão contadas ocorreram devido a escolha por realizar a docência orientada (componente curricular obrigatório aos bolsistas dos cursos de mestrado e doutorado em educação) na disciplina de estágio curricular supervisionado. Foram dois semestres atuando nesta mesma disciplina, com turmas diferentes, com acadêmicos que estavam realizando o sétimo ou o oitavo semestre do curso. O intuito foi de experienciar as diferentes instâncias da docência no ensino superior em uma disciplina que vivencia os processos de formação de professores em artes visuais.

O texto foi organizado em três momentos: no primeiro compartilho o que pensamos enquanto objetivos para a disciplina de estágio e os conteúdos previstos para os encontros. No segundo, o que foi desenvolvido, os desvios, as rupturas e brechas produzidas no decorrer dos semestres. No terceiro, me proponho a escrever sobre o que estas experiências me fizeram pensar com relação ao professor-pesquisador e a potencialidade da problematização nesses espaços formativos.

\section{Sobre objetivos e propostas para os encontros...}

Escolhi trabalhar com a disciplina de estágio para situar-me nesse espaço educativo como doutoranda, onde realizava a docência orientada, mas também enquanto docente, que atuava na rede pública de educação com o ensino de artes visuais. Assim, as partilhas foram ricas, tanto para mim, que me senti desacomodada como professora, como para os acadêmicos por poder compartilhar sobre minhas experiências na escola.

O estágio curricular supervisionado, no curso de Artes Visuais, propõe trabalhar questões relacionadas a docência, tais como: aprender a ser professor no campo de atuação profissional frente às diferentes realidades; compreender a ação educativa como espaço de pesquisa e extensão; materializar roteiros de aula compartilhados com o professor orientador, executando o projeto de estágio, planejando e avaliando; reconhecer os diferentes setores da escola e seu funcionamento; discutir a formação docente e buscar suporte teórico para a prática educativa no ensino fundamental e médio.

Ao planejarmos os encontros, intentamos problematizar a relação entre o professor pesquisador e a profissionalização, os roteiros de uma aula, de um projeto e de processos colaborativos, o exercício da docência na escola e o reconhecimento das 
funções administrativas e outros setores. Assim sendo, os encontros foram planejados de modo a trabalhar a pesquisa no campo de atuação, o contexto escolar e sala de aula, isto é, a inserção dos acadêmicos nas escolas ou em outros espaços educativos, acompanhando e observando as ressonâncias das leituras, orientações, discussões e estudos coletivos realizados nas aulas de estágio semanais em espaço universitário, bem como, se as mesmas foram operadas diante das realidades encontradas no sistema escolar e como se deu a articulação entre os estudos no espaço acadêmico com o espaço escolar.

A elaboração do projeto de ensino e pesquisa e dos planos de aula, por parte dos estagiários, ocorreuatravés de dois movimentos: primeiro foi solicitado aos acadêmicos que enviassem o queproduziram à professora da disciplina e à mim, para realizarmos uma leitura prévia, e em seguida, apresentassem aos colegas o que foi pensado, argumentando sobre a escolha do tema e de seus interesses de pesquisa, para que houvesse a contribuição de todos neste processo.

As aulas na universidade contaram com estas apresentações, com os relatos das práticas pedagógicas, bem como, com o estudo coletivo de textos e materiais selecionados. Os seminários foram pautados em leituras, pesquisas, experienciações com imagens, narrativas fílmicas e discussões. Em um dos semestres, o livro trabalhado no decorrer dos encontros foi proposto pela professora regente, e no outro, os textos foram escolhidos pelos acadêmicos. Os temas abrangeram como área em comum: a docência, o campo da arte, as problematizações sobre a filosofia e a educação, e os desafios da escola no contexto contemporâneo, tendo em vista que, a mudança na escolha do material foi devido a uma sugestão proposta pelos próprios acadêmicos na avaliação das aulas, referentes ao primeiro semestre que estive trabalhando nesta disciplina.

Sobre o livro escolhido no primeiro semestre, a temática propôs pensarmos a escola sob o viés das possibilidades e potencialidades da educação. No segundo, foram trabalhados nove textos, escolhidos pelos acadêmicos de acordo com seus interesses de pesquisa e vinculados ao tema de seus projetos: o visível e o enunciável (campos de visibilidade na educação e nas artes) (JUNIOR, 2015); aprendizagem, arte e invenção (pensando o conceito de aprendizagem) (KASTRUP, 2001); infância, memória e cinema (as narrativas fílmicas como potencializadoras para trabalhar as infâncias e a memória) (GOUVÊA, 2006); experiência (repensando o conceito de experiência como acúmulo, mas enquanto acontecimento) (BONDÍA, 2002); imagens (problematizar o que produzimos com as imagens e como as utilizamos nas aulas de artes visuais) (MITCHELL, 2015); a

Revista Digital do LAV - Santa Maria - vol. 9, n. 2, p. 261 - 273. - mai./ago. 2016 ISSN 1983 - 7348 http://dx.doi.org/10.5902/1983734823234 
formação do professor-pesquisador e a criação pedagógica (pensar o ato de criação a partir das filosofias da diferença) (CORAZZA, 2011); diferença e identidade (a interdependência destes conceitos e o como os mesmos podem ser pensados nas escolas de forma propositiva, e não apenas como forma de reforçar a diferença, mas como produção) (SILVA, 1998); as infâncias e a educação (pensar sobre a potência inventiva infante e o tempo do aion) (KOHAN, 2010); literatura (a literatura como possibilidade de pensar na educação e nos processos formativos docentes) (MARTIN, 2011).

Os textos selecionados previamente eram lidos por todos e apresentado cada semana por um acadêmico que buscava trazer outros elementos para pensar os conceitos do texto: imagens, artistas, vídeos, etc.

Em concomitância, foi proposto aos acadêmicos a elaboração de diários de aula (ZABALZA, 2004), a fim de potencializar o olhar deles para com as práticas pedagógicas, pensar nos processos que estariam vivenciando, e na provocação de tentar produzir relatos não lineares e não cronológicos, de lidar de forma propositiva com o ocorrido em sala de aula e não como lamúria. Por fim, solicitamos que todas estas atividades realizadas nos encontros, pudessem ser compartilhadas na escrita de um artigo científico, produzida e orientada ao longo do semestre.

Enquanto procedimento avaliativo, utilizamos vários instrumentos que pudessem dar conta de avaliar o processo de construção e a participação efetiva do acadêmico na disciplina. Contamos com a observação da postura com que o mesmo participou das leituras e seminários propostos, contribuição para com o grande grupo, no envolvimento com as práticas em sala de aula, no planejamento e desenvoltura diante dos estudantes, nas apresentações dos conceitos que embasaram sua pesquisa, nas propostas de trabalho e dos resultados parciais e finais apresentados através do diário/narrativa, bem como, a realização de uma autoavaliação na metade do semestre, e na entrega do artigo.

Para avaliar tais tarefas, foram desenvolvidos os seguintes instrumentos: questionário para a autoavaliação, ficha com critérios pontuais para as assistências das aulas nas escolas (preenchidas por nós que realizamos as visitas), questões como dispositivos ${ }^{1}$ para elaborar a apresentação dos resultados parciais e finais, procedimentos a serem contemplados no projeto de estágio e nos planos de aula, e

\footnotetext{
${ }^{1}$ Para Agamben (2009), um dispositivo é o que se produz entre a proposta e o exprimível.
} 
normas científicas na escrita do artigo, onde o mesmo contemplasse uma retomada de todos os processos percorridos na disciplina durante o semestre.

\section{Alguns desvios, rupturas e brechas...}

Apresentado os objetivos da disciplina, o que propusemos aos acadêmicos e como articulamos os conteúdos com as atividades, é hora de pensar no percurso, compartilhar o que foi desenvolvido, dar visibilidade aos desvios, as rupturas e brechas produzidas. Conversar com as leituras, que na sua multiplicidade, potencializaram pensar a formação docente e a pesquisa no campo da educação.

A possibilidade de acompanhar por dois semestres consecutivos, a mesma disciplina, permitiu olhar para o processo, para o percurso, observar as singularidades de cada turma, o amadurecimento de alguns projetos, o desdobramento de alguns temas. Vi alguns acadêmicos abandonarem suas temáticas de pesquisa, devido o encontro com outro tema em uma aula no estágio anterior, vi também, o quanto as leituras se intensificaram, e por sua vez, produziram escritas mais concisas.

Pensei então sobre as aulas que tinha participado, na universidade e de outros espaços durante as assistências, afinal, o que são as aulas? As aulas que planejei, as aulas que assisti e as aulas que produzimos coletivamente? O filósofo Deleuze (1988-1989) diria que uma aula é uma longa preparação para se ter inspiração, são ensaios, de modo que consigamos falar de algo com entusiasmo, achar a matéria que abraçamos fascinante. Um espaço-tempo especial onde muitas coisas acontecem, se estende de uma semana a outra, há uma seqüencialidade.

A partir da perspectiva que abordo este texto, uma aula não é dada porque não temos uma aula pronta para dar, nós produzimos uma aula no coletivo, ela é sempre acontecimento, é sempre inaugural.

Para mim, uma aula não tem como objetivo ser entendida totalmente. Uma aula é uma espécie de matéria em movimento. É por isso que é musical. Numa aula, cada grupo ou cada estudante pega o que lhe convém. Uma aula ruim é a que não convém a ninguém. Não podemos dizer que tudo convém a todos. As pessoas têm de esperar. Obviamente, tem alguém meio adormecido. Por que ele acorda misteriosamente no momento que lhe diz respeito? Não há uma lei que diz o que diz respeito a alguém. $O$ assunto de 
seu interesse é outra coisa. Uma aula é emoção. É tanto emoção quanto inteligência. Sem emoção, não há nada, não há interesse algum. Não é uma questão de entender e ouvir tudo, mas de acordar em tempo de captar o que Ihe convém pessoalmente. É por isso que um público variado é muito importante. Sentimos o deslocamento dos centros de interesse, que pulam de um para outro. Isso forma uma espécie de tecido esplêndido, uma espécie de textura. (DELEUZE, 1988-1989).

Nossas aulas de estágio foram um pouco disso, de uma semana à outra éramos diferentes, as aulas não eram as mesmas, de uma assistência à outra, os acadêmicos em formação docente eram outros, de um semestre à outro os encontros foram repensados. Tal como a frase dita por Deleuze (1988-1989) "Uma aula ruim é a que não convém a ninguém. Não podemos dizer que tudo convém a todos". O livro do primeiro semestre, que talvez não tenha afetado tanto, deu espaço a uma sugestão, e das escolhas por alguns assuntos, as aulas se tornaram emoção, não só pelo tema de quem escolhia o texto, mas por nos deslocar a conhecer o interesse dos colegas.

Era uma das rupturas, um dos borramentos de fronteiras, pois a diversidade de temas escolhidos solicitou mais leitura e mais estudo de todos, de arriscar-se, adentrar o perigo, aos campos desconhecidos. Alguns textos nos impulsionaram a dizer o que não pretendíamos fazer, o modo como não gostaríamos de trabalhar, outros textos solicitaram relações com as demandas da escola, outros com a necessidade da pesquisa no campo da educação e arte.

Conseguimos estabelecer como proposta de estudo dos textos, a problematização (FOUCAULT, 2013), isto é, pensar o texto enquanto uma conversa, em espaços de relações, e não de oposições. Foucault (2013) propõe pensarmos na problematização como forma de sairmos da lógica da polêmica associada ao discurso, à dialética, como uma prática de debate, do sistema de um tribunal onde se pronuncia o veredito e lança a condenação. De todo modo, o polemista diz a verdade na forma dejulgamento e de acordo com a autoridade que ele próprio seatribuiu. A polêmica define alianças, recruta partidários, produz a coalizão de interesses ou opiniões, representa um partido.

Assim, não tivemos a intenção de encontrar uma verdade, de estabelecer um pensamento único para cada tema em discussão, tampouco, de ficarmos confrontando ideias e juízos de cada um. Trabalhar a problematização é produzir abalos nos territórios conhecidos, é tentar sair dos "achismos" e dos conhecimentos relativos ao senso comum. 
No texto "A produção social da identidade e da diferença", Silva (1998) trabalha com questões bastante discutidas no cenário atual da educação, o chamado "multiculturalismo" e a diferença, que se apóiam em um vago e benevolente apelo à tolerância e ao respeito para com a diversidade. Tomaz Tadeu da Silva (1998) propõe que pensemos nestas teorias:

\begin{abstract}
Mas será que as questões da identidade e da diferença se esgotam nessa posição liberal? $\mathrm{E}$, sobretudo: essa perspectiva é suficiente para servir de base para uma pedagogia crítica e questionadora? Não deveríamos, antes de mais nada, ter uma teoria sobre a produção da identidade e da diferença? Quais as implicações políticas de conceitos como diferença, identidade, diversidade, alteridade? O que está em jogo na identidade? Como se configuraria uma pedagogia e um currículo que estivessem centrados não na diversidade, mas na diferença, concebida como processo, uma pedagogia e um currículo que não se limitassem a celebrar a identidade e a diferença, mas que buscassem problematizá-las? (p.1).
\end{abstract}

Na discussão, estabelecemos alguns pontos de convergência em relação ao que o texto propôs: a identidade e a diferença são inseparáveis, só conseguimos estabelecer uma identidade porque há diferenças, diversidades, que são resultados dos atos de criação, isto é, produzidas pelo ser humano nas relações culturais e sociais, nomeadas através da linguagem. O tema veio ao encontro de algumas temáticas que os acadêmicos estavam trabalhando nos projetos de estágio, como a diversidade racial, de gênero e sexual.

A problematização do texto ampliou nosso pensamento em torno do exercício de tolerância e reconhecimento das diferenças, destas identidades, pois expõe a identidade enquanto delimitadora de fronteiras, classificadora do que está dentro e do que está fora, por meio de uma política hierárquica. Sendo assim, a conversa produziu no coletivo a ideia de que mesmo que surjam outras denominações, outras identidades, para abarcar aqueles sujeitos que não se enquadram nas classificações já existentes, seria da ordem da identidade, teria a mesma lógica de incluir e excluir, dos que se enquadrariam então nessa nova identidade, e dos que não pertenceriam a mesma.

No texto em questão, Silva (1998) finaliza sua escrita, pontuando as possíveis abordagens deste assunto na escola, como é comumente trabalhado e como poderia ser pensado. Uma "estratégia pedagógica e curricular de abordagem da identidade e da diferença que levasse em conta as contribuições da teoria cultural 
recente" (p.8), baseada no pós-estruturalismo. Segundo o autor, seriam pensadas como questões políticas e a discussão estaria em torno da produção das mesmas. As perguntas cruciais implicariam em perguntar "como a identidade e a diferença são produzidas? Quais são os mecanismos e as instituições que estão ativamente envolvidos na criação da identidade e de sua fixação?" (p.8).

Para que isso aconteça, uma estratégia que apenas admita e reconheça o fato da diversidade, torna-se incapaz de fornecer instrumentos para questionar os mecanismos e instituições que fixam as pessoas em determinadas identidades culturais e que as separam por meio da diferença cultural (SILVA, 1998). Assim, é preciso adotar uma teoria que explique o processo de produção da diferença e da identidade:

\begin{abstract}
Antes de tolerar, respeitar e admitir a diferença, é preciso explicar como ela é ativamente produzida. A diversidade biológica pode ser um produto da natureza, o mesmo não se pode dizer da diversidade cultural. A diversidade cultural não é, nunca, um ponto de origem: ela é, em vez disso, o ponto final de um processo conduzido por operações de diferenciação. Uma política pedagógica e curricular da identidade e da diferença tem a obrigação de ir além das benevolentes declarações de boa vontade para com a diferença. Ela tem que colocar no seu centro uma teoria que permita não simplesmente reconhecer e celebrar a diferença e a identidade, mas questioná-las. (SILVA, 1998, p.9).
\end{abstract}

Assim, pudemos pensar nos efeitos de uma proposta pedagógica que considere estas questões, nas mudanças necessárias no modo de abordagem. De momento, os acadêmicos que estavam trabalhando com temas relacionados a diversidade racial, de gênero e sexualidade, compartilharam o modo como vinham trabalhando e o quanto precisariam repensar suas práticas, visto que, a maioria deles tratava do tema enquanto aceitação e tolerância às diversidades.

Dentre outras leituras, o texto que discutimos sobre experiência (BONDÍA, 2002) também ressoou na escrita dos artigos dos acadêmicos, e principalmente, no modo de pensarem suas práticas educativas e o contato com os estudantes. Quando tratamos deste assunto, discutimos alguns discursos presentificados nas escolas, tais como: "escute a voz da experiência", "eu tenho muitos anos de prática em sala de aula", "eu sei dar aula". Desdobrando estas frases, poderíamos problematizar o que esta professora compreende por prática? Segundo, a experiência seria o tempo 
passageiro como acúmulo de conhecimentos? E por último, o que seria saber dar uma aula?

Costuma-se pensar a educação do ponto de vista da teoria e prática, da relação entre ciência e a técnica. Uma teoria remete a perspectiva política e crítica, e a outra a uma perspectiva positiva e retificadora. Para a primeira, palavras como "reflexão", "reflexão sobre a prática ou não prática" tem sentido, visto que, os sujeitos críticos, se comprometem com maior ou menor êxito sobre as práticas educativas. No segundo, as pessoas que trabalham com educação são concebidas como técnico que aplicam com maior ou menor eficácia as tecnologias pedagógicas (BONDÍA, 2002).

Os resquícios destas teorias são facilmente percebidos nas frases pronunciadas pelos professores, principalmente aqueles que tiveram em sua formação tais perspectivas. Nas últimas décadas o campo educacional tem pensado outras questões e se distanciado dos chamados críticos e técnicos.

Assim, a abordagem que Bondía (2002) propõe sobre experiência, à relaciona com a produção de sentido. A palavra vem do latim, experiri, que significa experimentar, provar. Para o autor, é um encontro ou uma relação com algo que se experimenta, que se prova. Em outras etimologias se relaciona com a ideia de travessia, passagem, perigo.

O sujeito da experiência é como um território de passagem, passagem da existência de um ser que não tem essência ou razão, mas que existe de modo singular, imanente, contingente (BONDÍA, 2002). Por isso, a experiência é algo que nos toca, nos passa, nos deixa registros, vestígios. Ela é exterior à mim, estrangeira, depende da aparição de alguém ou de um acontecimento que está fora de mim, que não pertence ao meu lugar. Não se trata de interiorizar, nem de identificar, mas de uma saída de si para outra coisa, de experimentar algo que me é desconhecido.

Contagiamo-nos com estas definições, a ponto de nos confortarmos com os discursos proferidos nos espaços educativos, a ponto de pensarmos tais afirmativas como desacomodadoras, ou então, compreendermos como forma de defesa dos profissionais que estão a mais tempo nesses espaços e não conseguem ou não sabem lidar com teorias que diferem das suas. Esse exercício de respeitar o posicionamento do outro, e de argumentar sobre aquele que à mim faz mais sentido, foi realizado durante todos os encontros nas aulas de estágio. Intentamos fazer com que os professores em formação inicial pensassem estas situações de

Revista Digital do LAV - Santa Maria - vol. 9, n. 2, p. 261 - 273. - mai./ago. 2016 ISSN 1983 - 7348 http://dx.doi.org/10.5902/1983734823234 
forma propositiva, não de enfrentamento, mas de produção de conhecimento, de nos firmarmos diante do que queremos ou não na docência.

\section{O que esta experiência fez pensar... professor - pesquisador... criação...}

Na tentativa de finalizar esta escrita, gostaríamos de informar ao leitor que foram recortes das experiências ocorridas, sim, é preciso deixar evidente que não daríamos conta de totalizar o que foi proposto, desenvolvido e problematizado, nem foi de nossa intenção olhar para os encontros deste modo.

Compartilhar o trabalho que desenvolvemos em dois semestres, na disciplina de estágio curricular, foi de suma importância à nós que revisitamos os encontros, repensamos nossas maneiras de estarmos docentes nesse espaço. Não sentimos a sensação de "dever cumprido" por trabalhar com a formação docente, caso tivéssemos sentido isto, entenderíamos a existência de "verdades" a serem "ensinadas", "transmitidas", da detenção do conhecimento. Foram trocas, redes de partilhas, sentimos que propusemos leveza ao trabalhar com assuntos demasiadamente "pesados" na educação.

Gostaríamos de salientar o quanto trabalhamos a fundamentação teórica nos projetos de ensino (e pesquisa) e planos de aula, que segundo os próprios graduandos, possibilitou mais segurança nas práticas pedagógicas, enriquecimento das aulas, a continuidade e coerência no planejado.

As autoavaliações trabalhadas nos possibilitaram acompanhar o processo de formação de professores, pois nos trouxe o olhar dos acadêmicos sobre os materiais estudados, as experiências deles como docentes, a produção dos diários de aula e dos relatos, e a relação com a pesquisa, na escrita do artigo. Segundo os mesmos, as aulas de estágio lançaram: aprender a ouvir mais; estar aberto; tranquilo perante a turma; se relacionar com os estudantes para pensar nas aulas; estar atento ao planejamento, que pode auxiliar e interferir nas aulas; a importância dos relatos, pois compartilham dúvidas e anseios dos demais colegas, compartilham artistas, atividades, autores/leituras; trabalhar com um tema que é do nosso interesse, repensar conceitos e concepções sociais como em torno da infância e da família; como trabalhar com a história da arte de forma mais dinâmica?; Como fazer os estudantes se afetarem pela aula?; O que é obvio para mim é para o outro?.

Revista Digital do LAV - Santa Maria - vol. 9, n. 2, p. 261 - 273. - mai./ago. 2016 ISSN 1983 - 7348 http://dx.doi.org/10.5902/1983734823234 
Sendo assim, pensamos que mais do que cumprir com as exigências de uma disciplina que trabalha com a formação de professores, das demandas de atuar na escola, de planejar projetos e aulas, de pensar sobre o ocorrido na docência, instalamos e incitamos os graduandos a pesquisarem, a tomar gosto pela leitura, pelo olhar embebido de autores, de perspectivas teóricas, e abordagens metodológicas.

Como nos fala Corazza (2011, p. 12) sobre a docência "sempre foi pesquisa; e viceversa". Ainda que os sistemas educacionais (com os seus motivos) tenham inventado e divulgado um mito de que existiriam dois grupos, um com poucos profissionais da educação que pesquisam, enquanto no outro haveria uma grande massa daqueles professores que somente ensinam. "Talvez, tenhamos sido nós próprios, educadores, quem, sem questionar, passamos a acreditar nessa divisão em castas; e que, até, tenhamos desejado acreditar nisso" (p. 12). Por comodidade, talvez nem fizéssemos questão de nos considerar como pesquisadores, delegando a outros essa função, e dividindo o mundo da educação entre os que pesquisem, pensem, escrevam e publiquem e os que apenas ensinam.

Sob outros campos teóricos, como o pensamento das filosofias da diferença, docência sem pesquisa não existe, nunca existiu, nem existirá. Isto é, quem trabalha com a educação, não "dá" uma aula (voltamos ao pensamento deleuzeano sobre uma aula), assim como, não dá conselhos, conteúdos, afetos, etc., mas produz, os lança aos encontros, emite signos. Assim como Kastrup (2001, p. 26) nos fala sobre a aprendizagem, "o professor é um atrator, embora o atrator não seja necessariamente um professor. O atrator é uma função: define-se por seu poder de atrair, de arrastar-se consigo". Essa função pode ser desempenhada por um companheiro, ou por uma matéria, no entanto, tendo um professor, ele atrai para a matéria e não para um saber pronto.

Ele atrai não para junto de si, mas para o devir da matéria, para fluidez, ele conduz a expedição a um mundo desconhecido, de acontecer o contato, de potencializar intimidades, de acompanhar o processo. Nesse agenciamento professor-aluno, é que acontece a proliferação de possíveis, de ramificações, de propagações, onde os resultados não são pré-conhecidos e nem garantidos. O saber não é aquele de "acumular e consumir soluções, mas de experimentar e compartilhar problematizações, e a adoção da arte como ponto de vista faz parte desta política" 
(KASTRUP, 2001, p.26). Deste ponto de vista, "a aprendizagem é, sobretudo invenção de problemas, é experiência de problematização" (p. 17).

Em educação, na docência, nossa potência, nossa força, nossa vontade de educar, as energias, feitas de velocidades e lentidões, que nos levam a permanecer educando, apesar de tantos fatores adversos e desanimadores, estão na invenção, na fabricação de coisas, e não na verdade que é coisa feita, posta e pronta. Consiste, justamente, essa condição de abrir um canal que procura; logo, que cria, e que é o canal da pesquisa.

\begin{abstract}
Ora, por sua natureza humana, a docência-pesquisa integra uma tipologia das ações que são feitas com, entre, acerca, junto, no encontro com humanos. Logo, ações que são, em menor ou maior grau, da ordem do acaso, da aventura, do acontecimento, da surpresa, da irrupção, da novidade, do caos. Ensinar (fazendo pesquisa) e pesquisar (ensinando) consistem, dessa maneira, em criar soluções e, ao mesmo tempo, enigmas. Numa frase pronunciada ou escrita; no olhar ou no sorriso de alguém; num raio de luz; numa hora do dia, alguma coisa se passa, que não existia antes; e um novo, um inédito se faz, mesmo que não consigamos apreendê-lo. (CORAZZA, 2011, p. 13).
\end{abstract}

Até mesmo naquilo que se apresenta como encontrado, há procura, há pesquisa, alguma coisa quis se realizar: o ato de criação, próprio aos humanos (CORAZZA, 2011). Criação, que o professor-pesquisador pode tomar gosto, e para tanto, precisa que seja pensado como possibilidade de existência, precisa que alguém instale, acione, semeie... quiçá tenhamos produzido no grupo de licenciandos da disciplina de estágio curricular no curso de artes visuais, um pouco de invenção, de criação, de pesquisa na docência.

\title{
Referências
}

AGAMBEN, G. O que é o contemporâneo? E outros ensaios. Chapecó: Argos, 2009.

BONDIA, Jorge Larrosa. Notas sobre a experiência e o saber de experiência. Revista Brasileira de Educação, n.19, 2002, pp.20-28.

CORAZZA, Sandra Mara. A formação do professor-pesquisador e a criação pedagógica. Revista da FUNDARTE. Montenegro. Ano 11, no 21, p. 13 - 16.

DELEUZE, Gilles. O Abecedário de Gilles Deleuze. Realização de Pierre-André Boutang, produzido pelas Éditions Montparnasse, Paris. No Brasil, foi divulgado pela TV Escola, Ministério da Educação. Tradução e Legendas: Raccord [com 
modificações]. A série de entrevistas, feita por Claire Parnet, foi filmada nos anos 1988-1989.

FOUCAULT, Michel. Polêmica, política e problematização. Entrevista disponibilizada em maio de 1984, na internet. Disponível em: http://websmed.portoalegre.rs.gov.br/escolas/quintana/polemica_politica_problem atiz.htm. Acesso em 13 de fevereiro de 2013.

GOUVÊA, Maria Cristina Soares de. Infância, memória e cinema: nas imagens das origens, a origem da imagem. In: LARROSA, Jorge; CASTRO TEIXEIRA, Inês Assunção de; LOPES, José de Souza Miguel. A Infância vai ao Cinema. Belo Horizonte: Autêntica, 2006.

JUNIOR, José Carlos Sachetti. Extracampo: o visível e o enunciável - dois breves estudos. Linha Mestra, n. 27, 2015.

KASTRUP, Virgínia. Aprendizagem, arte e invenção. Psicologia em estudo, vol.6, n.1, 2001, pp.17-27.

KOHAN, Walter Omar (Org.). Devir-criança da filosofia - infância da educação. Belo Horizonte: Autêntica, 2010.

MARTINS, Isabel Minhós. Quando eu nasci. São Paulo, Tordesilhinhas, 2011. MITCHELL, W.J.T. O que as imagens realmente querem? In: ALLOA, E. (Org.) Pensar a Imagem. Belo Horizonte: Autêntica, 2015. pp.165 -189.

SILVA, Tomaz Tadeu da. A produção social da identidade e da diferença. In: Identidade e diferença. Belo Horizonte: Autêntica, 1998.

ZABALZA, Miguel. Diários de aula: um instrumento de pesquisa e desenvolvimento profissional. Porto Alegre: Artmed, 2004.

\footnotetext{
i Doutoranda do Programa de Pós-graduação em Educação (PPGE) Linha de Pesquisa LP4 - Educação e Artes; Mestre em Educação pelo Programa de Pós-graduação em Educação (PPGE) na Linha de Pesquisa LP4 - Educação e Artes (2015); Especialista em Tecnologias da Informação e da Comunicação Aplicadas à Educação (2013); Graduada em Artes Visuais - Licenciatura Plena em Desenho e Plástica (2011). Ambos pela Universidade Federal de Santa Maria (UFSM).
} 